\title{
IN MEDIA BARBARIA, ILLE EGO ROMANUS VATES: ETNOGRAFIA E AUTORIDADE NOS TRISTIA DE OVÍDIO
}

\author{
Cecilia Marcela Ugartemendía ${ }^{1 *}$ \\ Recebido em: 25/07/2019 \\ Aprovado em: 12/12/2019
}

\begin{abstract}
RESUMO: Durante seu exílio em Tomos, Ovídio escuda-se na ideia de declínio poético e linguístico, causado pela hostilidade do entorno. A adversidade do lugar em que deve cumprir a relegatio é o argumento para justificar a queda na qualidade de sua produção poética. Neste trabalho, propomos analisar aspectos da descrição etnográfica e geográfica apresentada por Ovídio nos Tristia 3.10 e 5.7, com o objetivo de adicionar mais elementos à longa tradição de estudos dedicados a demonstrar que a ideia de declínio é mais um artificio retórico na construção da persona relegata. Para tanto, a discussão será delimitada pela construção do eu poético como autoridade no tratamento do sofrimento do exílio. Em primeiro lugar, são analisados trechos de Tr. 3.10, dedicados à descrição etnográfica e geográfica da Cítia, na qual se destaca o manejo da sintaxe mimética. Em seguida, oferecemos diferentes observações sobre a já muito comentada intertextualidade entre esta epístola e a descrição da Cítia oferecida por Vírgilio em Geórgicas 3.349-83, destacando que as diferenças entre uma e outra descrição atendem à construção da autoridade de Ovídio como exilado, inclusive ao se arrogar o "direito de corrigir" o poeta anterior. Em segundo lugar, buscamos comprovar que, em Tr. 5.7, Ovídio relegatus continua a se construir como autoridade, reivindicando, no meio de sua aparente barbarização, seu lugar como grande Romanus vates.
\end{abstract}

PALAVRAS-CHAVE: Tristia; Ovídio; etnografia; autoridade poética.

IN MEDIA BARBARIA, ILLE EGO ROMANUS VATES: ETHNOGRAPHY AND AUTHORITY IN OVID'S TRISTIA

\footnotetext{
${ }^{1}$ A autora está sob orientação do Prof. Dr. Alexandre Pinheiro Hasegawa e é

bolsista FAPESP, a quem agradece pelo apoio financeiro para esta pesquisa.
}

* Doutoranda do Programa de PósGraduação em Letras Clássicas, Faculdade de Filosofia, Letras e Ciências Humanas, Universidade de São Paulo.

cecilia.7u@usp.br 
ABSTRACT: During his exile in Tomis, Ovid shields himself in the pose of poetic and linguistic decline, caused by the hostility of the environment. The adversity of the place where he must undergo the relegatio is an argument to justify his poetic production depreciation. The aim of this work is to analyze some aspects of the ethnographic and geographic depiction presented by Ovid in Tristia 3.10 e 5.7, in order to add more arguments to the long tradition of studies destined to prove that the pose of poetic decline is just another rhetoric means used in the construction of the persona relegata. We center the discussion in the construction of the poetic ego's authority on the treatment of the exile sufferings. Firstly, we analyze passages from Tr. 3.10, destined to the ethnographic and geographic depiction of Scythia, in which the domain of the mimetic syntax is underscored. Then, we offer some remarks on the already well commented intertextuality between this epistle and Vergil's Georgics 3.349-83, stressing that differences between one and the other are due to the construction of Ovid's authority as exile, having even the right to correct the previous poet. Secondly, we seek to prove that, in Tr. 5.7, Ovid relegatus continues to build his image as an authority, claiming, in the middle of his supposed barbarization, his place as great Romanus vates.

KEYWORDS: Tristia; Ovid; ethnography; poetic authority.

\section{INTRODUÇÃo}

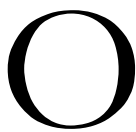

vídio, exilado em Tomos desde 8 d.C., dedica seu tempo à produção de duas obras (i.a.) epistolares, os Tristia e as Epistulae ex Ponto, que versam sobre o lamento por sua condição de relegatus e sobre sua defesa pessoal ante os duo crimina, ambas causas de sua condenação: carmen et error (Tr. 2.207). ${ }^{2}$ Nesses poemas, comumente catalogados como obras a respeito do exílio ovidiano, ${ }^{3}$ o poeta escreve sobre sua experiência como

\footnotetext{
${ }^{2}$ Há consenso em entender que o carmen teria sido a Ars amatoria, a qual iria contra as leis augustanas que buscavam preservar o matrimônio e a família. Sobre o error muito se especula, mas pouco se sabe. Segundo a hipótese mais comentada, Ovídio viu algo que não deveria ter visto. Isso se sustenta textualmente mediante referência direta a esse fato (Tr. 2.103-10) e diversos paralelismos estabelecidos pelo próprio Ovídio entre sua situação e personagens míticas que sofreram um castigo justamente por ter visto o que não deviam, como, por exemplo, Acteão (Tr. 2.103-10). Qual seria o error que levou o poeta ao exílio continua a representar para a crítica um problema difícil de elucidar. Não há registro histórico nem menção mais específica no próprio corpus ovidiano. Inclusive, houve interpretação de carmen et error como uma hendíade, que poderia ser lido como "o erro do poema" (Thibault, 1964, p. 36-7 apud Ingleheart, 2006, p. 64; Nagle, 1995, p. 3).

${ }^{3}$ Williams (1996) defende que Ibis deve ser lida também como um dos poemas que trata do exílio. Isso porque seria um ataque que revelaria o estado psicológico do poeta, que sucumbe à melancolia e se mostra, às vezes, como maníaco depressivo (p. 112-33). Williams chega a esta conclusão após rejeitar, no primeiro capítulo do estudo, a importância que tiveram a obra de Calímaco e outras obras helenísticas do mesmo gênero na elaboração do Ibis. A posição de Williams sobre a influência helenística é discutível. Porém, o mais extravagante é se tratar de leitura psiquiátrica (nem ao menos psicológica, como bem aponta Helzle, 1997), finalizando com o diagnóstico de Ovídio como depressivo e paranoico (Williams, 1996, p. 125). Parece-nos que uma abordagem como essa não evita a leitura
} 
relegatus e a dor pela separação da família, dos amigos e, sobretudo, de Roma. O sofrimento do poeta vê-se exacerbado: Ovídio é relegado a uma terra bárbara sem a possibilidade de comunicar-se por meio de sua poesia. Recorrendo de forma permanente à hipérbole, o poeta descreve a adversidade da situação em que se encontra. Por exemplo, embora as próprias condições climáticas da viagem que o levam a sua relegação já pretendam afastá-lo de seu labor, ele sempre ousa continuar a escrever (Tr. 1.11.41-2: improba pugnat hiems indignaturque quod ausim / scribere... / "o duro inverno luta e se indigna porque ouso escrever...”), ${ }^{5}$ desafiando as circunstâncias.

Por sua condição de exilado e pelo fato de que esse castigo aconteça numa terra em que o latim não é a língua principal, Ovídio é reduzido à condição de relegação cultural. Essa condição o priva do poder de fala no âmbito da sociedade romana, mas também fora dela, já que tampouco lhe é possível se comunicar na língua de seus hóspedes: os getas. Dessa forma, a escrita, i.e., sua poesia, passa a ganhar um lugar primordial como meio de comunicação. Para fazer-se ouvir - ou, no caso, ser lido - desde as margens do império, o poeta deve estar dotado da necessária autoridade, e é precisamente o que ele consegue com sua poesia. Ovídio passa de um relegatus sem poder de fala a alguém que obtém para si e para sua obra o status de referência como modelo de exilado e como modelo de uma poética do exílio.

$\mathrm{Na}$ criação da persona exilada por antonomásia, Ovídio configura um relegatus que perde não apenas o direito de viver em sua cidade, mas também a própria fala. O domínio da língua latina, intrínseca ao fazer poético ovidiano, sofre tanto quanto o poeta, principalmente por conta da barbárie que caracteriza seu inapelável lugar de relegatio. Para colocar no centro do que Claassen (1988, p. 168) chamou "o mito do exílio" um poeta relegatus, Ovídio deve

autobiografista do poema, além de desdenhar a tradição poética na qual está inscrito Ovídio já desde o próprio título da obra (o poema invectivo de Calímaco, do qual não sobrevive nenhum fragmento, leva também o nome Ibis). Martin (2004, p. 9), por sua vez, admite a leitura de Williams. Segundo a autora, no entanto, isso não mudaria o fato de que o tema do poema não é propriamente o exílio, mas sim a persecução de um inimigo por meio de vitupérios.

${ }^{4}$ Para o texto latino dos Tristia, seguimos a edição de Luck (1967). Para Epistulae ex Ponto, André (1977).

${ }^{5}$ Todas as traduções do latim para o português são nossas.

6 "Se se conclui que as obras do exílio são estilisticamente a culminação de uma carreira singularmente frutífera de um talentoso poeta, então segue-se que o poeta, em sua particular e estilizada descrição do exsul, assumiu o papel de vates, o cantor de verdade poética atemporal. Esta "verdade poética" encontra-se na esfera transcendental de um mito existencial: o mito do exílio. Isto é algo diferente de dizer que o exílio de Ovídio é fictício. Ele converteu o exílio de um aristocrata romano a uma cidade Greco-trácia nos anos finais do regime de Augusto em um estado heroico." "'If one concludes that the exilic works are stylistically the culmination of the singularly fruitful career of a talented poet, then it follows that the poeta, in his particular, stylized depiction of the exsul, has assumed the role of vates, the singer of timeless poetic truth. This "poetic truth" lies in the transcendental sphere of an existential myth: the myth of exile. This is something different from saying that Ovid's exile is fictitious. He has converted the exile of a Roman aristocrat, to a Graeco-Thracian city during the closing years of Augustus' regime, into a heroic state." Claassen, 1988, p. 168). Ver também Claassen (1999, p. 68-72). Todas as traduções dos textos em línguas modernas para o português são nossas. 
também recriar as condições geográficas em que se encontra, que determinam por si as condições de produção da poesia no exílio, os temas, a atitude do poeta diante da adversidade e - como ele argumentará - a própria qualidade da poesia. Em seguida, serão analisados dois poemas pertencentes aos Tristia em que Ovídio delineia a etnografia e a geografia tomitanas, responsáveis pelo conteúdo da novidade poética que representa em sua oeuvre a poesia do exílio. Ao analisar o discurso sobre a etnografia e a geografia do lugar designado para cumprir o castigo, vemos como Ovídio, ao opor-se às pessoas e aos costumes do seu novo lar, constrói sua autoridade como cidadão romano e como poeta.

\section{A “POSE DO DECLÍNIO POÉTICo"}

Tristia 3.10 e 5.7, por sua temática etnográfica, podem ilustrar a influência de Tomos tanto no tipo de poesia ali produzida como na qualidade dela. Nestas epístolas Ovídio descreve o lugar em que está exilado e o povo com quem é forçado a conviver. O lugar e seus habitantes são inapropriados como fonte de inspiração poética, o que alteraria a virtude compositiva do vate. O lamento pela adversidade do lugar do exílio reflete-se, segundo o poeta, em uma poesia de inferior qualidade. ${ }^{7}$ Williams chamou a queixa constante sobre a inferioridade de sua poesia de "pose de declínio poético" (Williams, 1994, p. 50), , a qual seria parte do jogo de simulação próprio do poeta em seu papel como exilado exemplar. $\mathrm{O}$ lamento pela qualidade da poesia é mais uma ferramenta retórica para a manifestação da dor pela relegatio.

Helzle interpreta essa postura de declínio como decorosa com o tema e a monotonia que o lugar de seu exílio implica: "O princípio de to prepon finalmente explica a monotonia da matéria de Ovídio nos Tristia e nas Epistula ex Ponto, que tem sido criticada com frequência. Se a vida em Tomos é monótona, a poesia do exílio necessariamente deve refletir esta monotonia" (Helzle, 1989, p. 17). ${ }^{9}$ Ou seja, para o autor haveria determinação geográfica sobre a qualidade da poesia de Ovídio. Claassen, por sua vez, arrisca defender que a afirmação da inferioridade da poesia do exílio feita pelos estudiosos da obra surge, na verdade, a partir de uma afirmação do próprio poeta:

A tradição calimaquiana da recusatio, que apresenta uma visão ostensivamente difamatória dos próprios logros literários de um poeta, particularmente nos gêneros "menores" da elegia e a lírica, é subjacente à ostensivamente negativa autocrítica da obra do exílio. $\mathrm{O}$ orgulho concomitante e contraditório em seus logros e a confiança em sua Musa oferecem mais um apoio à ainda frequente opinião

\footnotetext{
${ }^{7} \mathrm{~A}$ inferioridade de sua qualidade poética e linguística é tema já amplamente estudado, especialmente em Nagle (1980, p. 139-41) e Williams (1994, p. 50), i.a.

8 "Ovid's pose of poetic decline".

9 "The principle of to prepon finally explains the monotony of Ovid's subject matter in the Tristia and Exponto which has often been criticized. If life in Tomi is monotonous the exile-poetry necessarily has to reflect this monotony".
} 
crítica de que "tal como o poeta pensou que estes poemas são ruins, eles devem ser inferiores e decadentes" (Claassen, 1988, p. 167). ${ }^{10}$

Casali, por outro lado, propõe instigante leitura da postura de declínio como justificativa pela mudança do tema de suas elegias:

Deve surgir uma dúvida - a dúvida de que Ovídio possa estar inventando pretextos ante seu leitor modelo não pelos erros alegados de sua ars e ingenium, senão que ele esteja inventando pretextos, em forma bastante perigosa, por outra coisa. [...] Na minha opinião, então, quando Ovídio se desculpa com o leitor pela feia compleição de sua poesia do exílio, ele se desculpa pelo que em verdade é uma das mais novas caraterísticas dessa poesia: ele se desculpa pelo fato de estar coagido a escrever versos lisonjeiros (Casali, 1997, p. 89). ${ }^{11}$

A pose de declínio seria, segundo Casali, uma forma de reconhecer a submissão forçada a escrever um tipo de poesia que não lhe é próprio, e com o qual tampouco comunga.

O artifício da "pose de declínio" como algo meramente fictício é desvelado mediante a análise dos poemas, que revelam destreza na composição poética. As duas epístolas analisadas a continuação servem como exemplo disso. Por um lado, a descrição etnográfica apresentada em Tr. 3.10 e 5.7 desborda em tropos e figuras que jogam com a sintaxe e semântica do texto. Além disso, mediante a descrição do lugar, Ovídio trabalha sua própria autoridade poética, fundamental no processo de construção da persona que é centro do mito do exílio.

Começaremos nossa análise com Tr. 3.10, primeira longa descrição do território tomitano, a partir da qual será destacada a destreza demostrada por Ovídio no manejo da sintaxe mimética, por meio da análise dos trechos dedicados à descrição etnográfica e geográfica da Cítia. Logo, discutiremos a forma como o autor real opera a construção do eu poético como autoridade no tratamento do sofrimento do exílio. Ademais, buscaremos comprovar que em $\operatorname{Tr} .5 .7$ - epístola fortemente ligada à anterior pela temática etnográfica - Ovídio relegatus continua a se construir como autoridade e destaca, apesar de sua aparente barbarização, seu lugar como vates romano.

\footnotetext{
10 “The Callimachean tradition of recusatio, presenting an ostensibly denigratory view of a poet's own literary achievement, particularly in the 'lesser' elegiac and lyrical genres, lies behind the ostensibly negative self-criticism of the exilic oeuvre. The poet's concomitant and contradictory pride in his achievement and reliance on his Muse offers a further counter to the still frequently held critical opinion that 'as even the poet thought these poems bad, they must be inferior and decadent".

11 "A doubt must arise - the doubt that Ovid may be making excuses before his model reader not for the alleged defects of his ars and ingenium, but that he may be making excuses, in a rather dangerous way, for something else. [...] In my view, then, when Ovid apologizes to the reader for the ugly complexion of his exilic poetry, he apologizes for what in reality is one of the newer features of that poetry: he apologizes for the fact that he is constrained to write flattering verse".
} 


\section{TR. 3.10: IN MEDIA VIVERE BARBARIA}

Tr. 3.10 é a primeira grande descrição do lugar em que se deu a relegatio de Ovídio. O poema foi composto durante o primeiro ano em Tomos (o segundo, desde que o poeta deixou Roma rumo ao exílio). A paisagem tomitana e o estilo de vida do lugar são colocados em oposição à vida na $V r b s$. Os três primeiros dísticos do poema dizem respeito à pretensão do poeta ao escrever seus versos, sobre o porquê de sua constante queixa e sobre o declínio de seu ingenium:

Siquis adhuc istic meminit Nasonis adempti, et superest sine me nomen in Vrbe meum,

suppositum stellis numquam tangentibus aequor me sciat in media vivere barbaria.

Sauromatae cingunt, fera gens, Bessique Getaque, quam non ingenio nomina digna meo! (Tr. 3.10.1-6)

Se, ali, alguém ainda se lembra de Nasão, arrebatado, e sobrevive, sem mim, meu nome na Urbe, que saiba que vivo em meio aos bárbaros, colocado sob as estrelas que nunca tocam o mar.

Rodeiam-me os sármatas, povo feroz, e os bessos e os getas; 5 quão indignos nomes para meu talento!

Tomos está localizada próxima à Cítia Menor, a atual Bósnia, Cróacia e parte da Romênia. Como apontado por Claasen, porém, Ovídio joga com a confusão entre a área norte - Scythia Maior, atual Ucrânia e Bielorrússia, ao norte do Mar de Azov (Lago Maeotis) - e Scythia Minor. ${ }^{12}$ Desta forma, ao aludir apenas à "Cítia", o lugar do exílio aparece como mais afastado ainda do que realmente estava. Este é um dos pontos criticados pelos defensores da ficcionalidade: a falta de exatidão na descrição da localização e mistura de topônimos e dos nomes das tribos que ali habitavam: getas, trácios, bessos, dácios, sármatas etc. A falta de rigor corresponde ao ponto de vista do romano que fala sobre o Norte, nomeando questões que se aproximam ao senso comum sobre o local e não precisamente buscam a exatidão dos fatos. Ovídio utiliza o campo semântico do Norte e sua representação poética para oferecer uma descrição que parte da oposição de Tomos com Roma. É o que se comprova,

${ }^{12}$ Claassen (1999, p. 191): "Ovídio explora a confusão geral na literatura antiga entre a área norte, Scythia Maior (ou propriamente Cítia), situada em Ucrânia e Bielorrússia, ao norte do Mar de Azov (Lago Maeotis), e Scythia Menor, ou Moesia, a atual Bósnia e Croácia e parte de Romênia. Na literatura romana, os selvagens habitantes de Moesia eram usualmente chamados Daci. Ovídio sempre usa o termo poético (grego) Getae (como em Virgílio e Horácio)." "Ovid exploits the general confusion in ancient literature between the northern area, Scythia Maior (or Scythia proper), situated in Ukraine or Belorus, north of the Sea of Azov (Lake Maeotis), and Scythia Minor, or Moesia, today's Bosnia and Croatia and parts of Roumania. In Roman literature, the savage inhabitants of Moesia were usually called Daci. Ovid always uses the poetic (Greek) term Getae (as in Vergil and Horace)." 
por exemplo, já no começo de Tr. 3.10, citado supra, na descrição da localização do poeta em terra bárbara no norte do império (3.10.4-5: suppositum stellis nunquam tangentibus aequor / me sciat in media vivere barbaria), sob as constelações da Ursa Maior e Menor. O local contrapõe-se a istic, v. 1, Roma, em que o poeta espera ainda ser lembrado apesar de relegado. O poeta pode estar fora de Roma, mas Roma não está fora do poeta.

Desde o livro primeiro dos Tristia ${ }^{13}$ é destacada a barbárie peculiar ao lugar do exílio. Esta caraterização não é novidade para o leitor contemporâneo do poeta, embora tenha particular importância nesta epístola. Ao fazer uma leitura diacrônica das cartas, a Tr. 3.10 segue a particular vinculação da origem do nome de Tomos (Tr. 3.9.2: "inhumanae nomen barbariae"14 / "nome de inumana barbárie") com o violento episódio do assassinato de Absirto por parte da sua irmã, Medeia, descrito em Tr. 3.9. O germe de violência e barbárie está, portanto, na própria etimologia do topônimo e na relevância da personagem de Medeia e sua condição de bárbara, como personagem principal em parte do mito fundacional tomitano.

Os assim chamados povos selvagens e a bárbara terra em que vivem são apontados como causa da decadência do seu ingenium (v. 4-7). Todavia, já no v. 3 há mostra da sintaxe mimética ovidiana, que permite "experimentar, mais do que apenas saber, o que autor quer dizer" (Stanford, 1967 apud Lateiner, 1990, p. 205) ${ }^{15}$ e que contradiz a pose de declínio poético do exilado. A palavra media encontra-se no meio do verso em que o poeta reclama viver no meio dos bárbaros (me sciat in media vivere barbaria), e o verbo vivere é inserido no meio do sintagma nominal da construção preposicional (in media vivere barbaria).

Seguindo a declarada falta de matéria para sua inspiração, começa a mais exaustiva descrição da paisagem danubiana e de Tomos apresentada até esse momento nos Tristia. Essa descrição, no entanto, é familiar para seu público, uma vez que retoma a digressão sobre a Cítia feita por Virgílio em Geórgicas 3.349-83. A persona ovidiana outorga a essa descrição uma maior carga patética, conforme o objetivo a atingir: o desenvolvimento de uma persona exiliada por antonomásia. ${ }^{16} \mathrm{Em}$ Lands and people in Roman poetry, Richard Thomas (1982) demonstra que a literatura romana segue a linha da prosa etnográfica grega. Em seu estudo, propõe uma série de elementos que compõem a tradição da descrição etnográfica: 1) a geografia física da área, 2) o clima, 3) a agricultura, recursos minerais etc., 4) origem e caraterísticas dos habitantes, e 5) a organização política, social e militar (Thomas, 1982, p. 1). Tal qual demonstrado por Thomas, a descrição da Cítia feita por Virgílio nas Geórgicas

\footnotetext{
${ }^{13}$ Ver Tr. 1.10 .31

${ }^{14}$ O nome refere-se ao grego $\tau \dot{\mu} \mu \nu \omega$, "cortar, machucar".

15 "Experience, rather than just know, what [an author] means".

${ }^{16}$ Concordamos com a seguinte afirmação de Claassen (1999, p. 190): "a maior parte dos detalhes físicos dados por Ovídio sobre seu lugar de exílio não pode ser tomada como um exagero que apenas precisa ser atenuado para ser aceitável como informação geográfica e etnográfica. Esses detalhes são propositadamente fantásticos e têm pouca, se é que têm alguma, relação com a realidade física." "The major parts of the physical details Ovid gives about his place of exile cannot be taken as exaggeration which merely needs toning down in order to be acceptable as geographical or ethnographic information. These details are purposely fantastic and have little if any relation to physical reality".
} 
abrange todos os pontos. Já a descrição ovidiana do local não faz parte do objeto de estudo do autor. Aplicando o esquema por ele proposto, pode-se comprovar que Ovídio também dá conta de todos esses elementos listados, o que caracterizaria suas linhas como propriamente etnográficas. Reproduzimos em seguida o esquema apresentado por Thomas, no qual indica a dependência de G.3.339-83 em relação à tradição etnográfica (Thomas, 1982, p. 37), e adicionamos a informação correspondente a $\operatorname{Tr}$. 3.10, resultado do nosso relevamento:

\begin{tabular}{|c|c|c|}
\hline Categoria & $\begin{array}{l}\text { Cítia Virgiliana }^{17} \\
\text { (G. } 3.349-383)\end{array}$ & $\begin{array}{c}\text { Cítia Ovidiana } \\
(T r .3 .10)\end{array}$ \\
\hline Geografia física & v. $349-51$ & v. $7-8,27-8$ \\
\hline Clima & v. $352-3$ & v. $9-18,25-6,29-34,37-53$ \\
\hline Agricultura e recursos & v. $354-9$ & v. $67-75$ \\
\hline Habitantes & v. $376-83$ & v. 5 \\
\hline Organização e caraterísticas sociais & v. $360-80$ & v. $19-24,54-66$ \\
\hline
\end{tabular}

Como se pode observar a partir do esquema, a severidade do clima acentuada por Ovídio constrói uma cenografia inclemente e opressiva para o habitat, que determina as condições de vida dos habitantes. Mas a principal diferença entre uma descrição e outra encontra-se no fato de que Ovídio encontra-se, sim, presencialmente no lugar a descrever. Contudo, há distanciamento por parte do exilado dos habitantes daquele lugar de que não faz parte. Ele é um romano cujos valores e tradições são opostos aos deste povo.

Esse distanciamento se percebe na descrição, por exemplo, das vestimentas dos getas. O frio é inclemente para todos, porém são eles, e não Ovídio, os que se cobrem com peles (Tr. 3.10.19:18 "pellibus et sutis arcent mala frigora bracis"/ "previnem-se dos daninhos frios com peles e calças cosidas"), prendas caraterísticas dos bárbaros, segundo a perspectiva romana. Também ao descrever o avanço do inimigo (Tr. 3.10.51-66), o eu poético é mero espectador da devastação e das terríveis consequências para os habitantes: "diffugiunt alii”" / "outros fogem" (v. 57); "pars agitur [...] capta"/ "uma parte é conduzida [...] cativa" (v. 61); "pars cadit [...] confixa sagittis" / "uma parte cai [...] atravessada pelas flechas" (v. 63); "tum quoque, cum pax est, trepidant" / "inclusive então quando há paz, tremem" (v. 67); "nec quisquam [...] sulcat humum"/ "e ninguém [...] ara a terra" (v. 68). Da mesma forma em que ele é testemunha, poderia sê-lo o romano que está a ler sua epístola, caso tivesse a oportunidade (aspiceres, v. 75). Tanto ele como seu leitor são outros frente a esses bárbaros, mesmo que, tempos mais tarde, esta diferença pareça se diluir.

Tanto em uma como em outra descrição repetem-se as mesmas qualidades e traços peculiares dos habitantes do lugar, retratados por Virgílio como "gens effrena virum"/ "etnia indômita de homens" (G. 3.382). Porém, por não ser mera digressão, mas o tema central do

\footnotetext{
${ }^{17}$ Reproduzimos apenas o número dos versos e não parte dos versos, como faz Thomas.

${ }^{18}$ A descrição da roupa repete-se também em Tr. 4.6.47; 5.7.49 e 10.33-4, sempre de modo pejorativo.
} 
poema, a caraterização ovidiana é abundante em detalhes, embora nas partes coincidentes haja algumas pequenas diferenças. Por exemplo, em G. 3.356, Virgílio descreve a força e persistência do vento apenas com quatro palavras: "semper spirantes frigora Cauri" / "sempre Coros soprando frios". Por sua vez, Ovídio dedica à força dos ventos um dístico:

Tantaque commoti vis est Aquilonis, ut altas aequet humo turres tectaque rapta ferat. (Tr. 3.10.17-8)

E tanta é a força do desencadeado Aquilão que deita à terra as altas torres e destelha os telhados. ${ }^{19}$

A descrição da ferocidade do vento é acompanhada pela aliteração do som sibilante que se repete ao longo do segundo hemistíquio do verso 17. Além disso, sua força transborda o verso no encavalgamento, que arrasa as torres e telhados do verso seguinte, e cuja derrubada é acentuada pela aliteração do /s/ e o / t/. A divergência com o verso virgiliano está no tipo de vento que arrosta a região: ao passo que Ovídio menciona o Aquilão, vento do nordeste, Virgílio menciona os Coros, ventos do noroeste. Isso pode ser interpretado como pequena correção introduzida pelo poeta exilado, que experimenta em primeira pessoa a adversidade climática do lugar.

Como mencionado supra, mesmo que a localização do Ponto seja em Moesia, Ovídio distingue continuamente seu lugar de relegatio como a Cítia, mais distante e exótica. Porém, Claassen (1990, p. 195) nota que Virgílio localizava a Cítia ao norte do mar de Azov, ao passo que Ovídio a localiza ao sudoeste, perto de Moesia, um lugar real (mesmo que sua descrição física continue sendo imaginária), melhorando a geografia do poeta anterior. Desse modo, Ovídio explora sua qualidade de exilado e sua capacidade para oferecer informação apropriada por ser testemunha direta. Ser exilado, ao fim das contas, confere-lhe autoridade para corrigir a reconhecida descrição anterior.

$\mathrm{Na}$ metade da descrição, após relatar a inclemência do frio que congela o rio, o poeta reconhece o incrível do relato e, portanto, afirma "vix equidem credar" / "de fato, dificilmente acreditarão em mim" (v. 35). Daí que, para continuar, destaque a relevância de ser testemunha ocular daquilo que é relatado, o que funciona como elemento que confere validade. ${ }^{20}$ Diferentemente de Virgílio, que aponta apenas o congelamento dos rios e a passagem de carros por sobre as águas (G.3.360-2), Ovídio desenvolve um longo trecho de alto conteúdo hiperbólico (Tr. 3.10.25-50). É notável neste trecho o manejo da língua na seleção lexical. Em vinte e cinco versos dedicados ao congelamento das águas, o poeta utiliza onze substantivos diferentes para se referir ao campo semântico de "água": rivus (v. 25), lacus (v. 26), aqua (v. 26, 30, 38, 42, 48), amnis (v. 27), fretum (v. 28), Hister (v. 29), mare (v. 30), unda (v. 33, 40), pontus (v. 37), aequor (v. 39), fluctus (v. 46). Segundo relata o exilado, o

\footnotetext{
${ }^{19}$ Tradução proposta por Pedro Baroni Schmidt (a quem muito agradecemos), que busca manter a aliteração assinalada.

${ }^{20} \mathrm{Da}$ mesma forma, na História da Guerra do Peloponeso, Tucídides reconhece que seu caráter de exilado lhe permitiu observar pessoalmente os acontecimentos que relata (5.26.5).
} 
frio congela não apenas os rios, mas também o próprio mar (Tr. 3.10.37: "vidimus ingentem glacie consistere pontum"/ "vi o ingente mar congelar-se"). Por ser uma situação pouco crível, Ovídio deve apoiar a veracidade de sua descrição com referências à vista e a outros sentidos que o colocam como testemunha de primeira mão: vidimus... (v. 37), nec vidisse sat est, ... calcavimus ... (v. 39), vidimus (v. 49). Mais tarde, em Pont. 4.7, escrita ao menos dois anos depois de Tr. 3.10 (talvez até quatro anos depois, segundo Helzle, 1989, p. 156-7), o poeta exilado tem a possibilidade de ratificar a descrição geográfica do Ponto ao ter agora uma segunda testemunha ocular que pode corroborar o dito: o prefeito romano Júlio Vestal. Novamente, para destacar o incrível da paisagem, Ovídio recorre ao sentido da vista, desta vez a de Vestal, com a tríplice anáfora ipse vides (Pont. 4.7.7, 8, 9) e aspicis (Pont. 4.7.11). O apoio de semelhante testemunha acaba, na última referência feita pelo exilado à paisagem danubiana, de validá-lo como autoridade para dizer sobre o tema.

Em Tr. 3.10.41-2 o poeta ilustra o congelamento do mar fazendo referência à impossibilidade que Leandro tivesse tido para nadar por essas águas congeladas, o que teria evitado sua morte por afogamento:

Si tibi tale fretum quondam, Leandre, fuisset, non foret angustae mors tua crimen aquae. (Tr. 3.10.41-2)

Se tu, Leandro, em outro tempo, tivesses tido tal mar, tua morte não teria sido crime de um estreito.

Logo após, reforça o absurdo da situação ao contar que os golfinhos não podem pular na água porque está congelada. No entanto, na sintaxe, Ovídio consegue, mediante o domínio da arte poética, o que na natureza agressiva do Ponto seria impossível, e há um salto na proposição ao verso seguinte. Assim, o poeta faz os golfinhos pularem, ao menos, de verso a verso, no encavalgamento do v. 43 ao 44: "Tum neque se pandi possunt delphines in auras/ tolere." / "Então nem mesmo os curvos golfinhos podem se elevar pelo ar" (Tr. 3.10.43-4). No final da epístola, nos versos 73-4, repete-se a referência a uma personagem da poesia amatória ao tratar sobre a infertilidade da terra:

Poma negat regio, nec haberet Acontius, in quo scriberet hic dominae verba legenda suae. (Tr. 3.10.73-4)

A região nega os frutos e neste lugar Acôncio não teria em quê escrever as palavras que deviam ser lidas por sua amada.

Tanto Leandro como Acôncio são personagens de poesia amatória ${ }^{21}$ e das elegias de Ovídio, se consideramos legítima a autoria das chamadas "Heroides duplas". Todavia, essas

\footnotetext{
${ }^{21}$ Se bem não há testemunhas sobre outros tratamentos de Leandro e sua amada Hero anteriores às Heroides 18 e 19 - com exceção de uma breve passagem nas Geórgicas, de Virgílio (3.258-63) -, supõe-se que a história desses amantes tenha sido bem conhecida na época em que Ovídio escreve seus Tristia, provavelmente, a partir da poesia helenística (Rosati, 1996, p. 11). Já a história de Acôncio e Cidipe, também de tradição helenística, encontra-se atestada em Calímaco, Aitia, 3, fr. 67-75.
} 
personagens e suas histórias de amor não têm lugar na poesia do exílio. Nestes versos, Ovídio demonstra a impossibilidade do tratamento do tema (Evans, 1975, p. 4), contrastando a temática adotada em suas elegias amorosas com a nova realidade imposta pela situação que atravessa e o local em que está. Desta forma, fica demonstrada a necessidade de mudança no conteúdo poético e, por conseguinte, da persona de sua poesia.

Assim, vimos que Ovídio em Tr. 3.10 utiliza termos e formas já conhecidas pelo público para descrever a paisagem distante e estranha que habita, alternando entre relato e reflexão poética (Holzberg, 1998, p. 178). Aquela paisagem virgiliana já conhecida é reelaborada, permeada pela visão do exilado como testemunha ocular. Para o relegatus, a relação intertextual com as Geórgicas funciona como argumento de autoridade e contribui para arrogar à sua própria descrição autoridade, dotada de detalhes hiperbólicos que agregam efeito patético. Concordamos com Claassen que o retrato feito pelo poeta do lugar de exílio é literário e que Ovídio insere sua descrição numa tradição poética que trata sobre a topografia deste lugar (Claassen, 1999, p. 191; também Holzberg, 2006, p. 56). Mas o que interessa aqui é o porquê. Essa inserção na tradição poética é necessária para a construção da autoridade da persona do poeta exilado, ao se ver descreditada por sua condição de relegata. Além disso, ele não apenas se insere numa tradição, mas também traz novos dados que lhe são conhecidos graças à condição de exilado. Neste ponto, Ovídio explora sua desgraça para torná-la uma vantagem que lhe confere autoridade. O poeta exsul está habilitado para descrever com propriedade o local em que se encontra e postula-se como autoridade para falar sobre a experiência no exílio, fim último destas epístolas.

\section{TR. 5.7: ILLE EGO ROMANUS VATES}

Diferentemente de Tr. 3.10, Tr. 5.7 é aberto com um explícito endereçamento epistolar, embora não se conheçam nem o destinatário nem a data de composição. Novamente, encontra-se uma caraterização da Cítia mais pertinente com a tradição poética do que com a descrição dos fatos. Nestes versos, a descrição etnográfica ganha mais peso do que a geográfica, e com ela também a oposição entre civilização e barbárie.

Tomos, como mencionado supra, tem uma origem grega e está dominada pelos male pacatae Getae (v. 12). Neste ponto, pode-se interpretar uma afronta à ideia da Pax augusta, uma vez que, assim como apontado em Tr. 3.10, os habitantes dessas regiões não vivem em paz. Apesar de que em Tr. 3.10 o inimigo era externo, em Tr. 5.7 a barbárie encontra-se intra muros. Os sármatas e getas percorrem a cidade armados e com flechas envenenadas (v. 15-6). Além disso, a descrição da imagem externa desse povo já não se limita ao rosto hirsuto e à vestimenta (v. 18, 49), dando-se ênfase a seu rosto selvagem (vox fera, trux vultum, v. 17) e a sua animalização (Tr. 5.7.45-6: "sive homines [specto] vix sunt homines hoc nomine digni, / quamque lupi, saevae plus feritatis habent"/ "ou se observo os homens, os homens mal são dignos deste nome e têm mais de cruel ferocidade do que os lobos"). Rodeado por tais pessoas, Ovídio passa o tempo dedicado a seus estudos (v. 39, 65-8). Da mesma forma em que, em Tr. 3.10, Leandro e Acôncio representavam exempla às avessas para este tipo de poesia, em Tr. 5.7 o poeta esclarece que nos novos versos escritos não haverá lugar para a 
poesia amatória: "Vivit in his heu nunc, lusorum oblitus amorum!" / “Ó, vive entre estes agora, esquecido de teus amores brincalhões!” (Tr. 5.7.21). Três versos antes há indício do porquê do abandono do tipo de poesia que o ocupava antigamente: os homens em Tomos não aparam seus cabelos ${ }^{22}$ (Tr. 5.7.18: "non coma, non ulla barba resecta manu"/ "nem os cabelos, nem a barba rasurada por mão alguma”), ignorando a recomendação do praeceptor amoris na Ars 1.518: "sit coma, sit trita barba resecta manu"/ "que os cabelos, que a barba seja rasurada por mão experiente”. A clara alusão autotextual - realçada não apenas pelo tema, mas também pelo paralelismo da construção sintática - ratifica que ele não se esqueceu de sua própria poesia (Williams, 1994, 20). Porém, essa poesia sofre uma transformação, uma metamorfose (mais uma no repertório ovidiano), que dá lugar ao lamento pelo exílio.

O poeta declara que não se preocupa em perseguir renome, embora seja grato por manter viva sua lembrança entre os romanos:

Non tamen ingratum est, quodcumque oblivia nostri impedit et profugi nomen in ora refert. (Tr. 5.7(b). 29-30)

Todavia, não é desagradável qualquer coisa que impede o esquecimento de mim e coloca na boca o nome de um exilado.

Nec tamen, ut lauder vigilo cure futuri nominis, utilius quod latuisset, ago. (Tr. 5.7(b). 37-8)

Todavia, não me mantenho acordado para ser louvado, nem me preocupo com um nome futuro o qual seria mais útil se ficasse oculto.

Percebe-se uma mudança de posição do relegatus a respeito de anos atrás, quando no começo de Tr. 3.10 (v. 1-6, citados supra) ele ressalta o próprio nome (Nasão) e escreve explicitamente informando sobre seu paradeiro e condição, buscando assim informar seus leitores sobre ele. Esta mudança de postura frente à procura da fama do poeta foi analisada por Michalopoulos (2016), que encontra nos livros quarto e quinto dos Tristia - últimos dois da coletânea - a "tendência de rejeitar a fama como uma meta de composição poética e mudança do objetivo do fazer poético, que agora é se distrair de suas circunstâncias” (Michalopoulos, 2016, p. 84), como se vê em Tr. 5.7.65-8.

Seria possível fazer uma ressalva em relação a esta última observação. Tanto na pose de declínio do poeta como na construção da identidade poética da persona exilada há uma coerência no desenvolvimento do caráter do exilado proporcional à passagem do tempo e, portanto, ao aumento da desesperança do poeta. Essa mudança de objetivo não deveria ser lida apenas como uma forma "para buscar consolo em suas adversidades e não como um meio de receber glória” (Michalopoulos, 2016, p. 94), mas como parte do desenvolvimento do caráter da persona exilada. No fim das contas, ele continua a enviar poemas a Roma, com vistas a perpetuar o nome dele, sua fama e importância como poeta. A Urbe não perde seu lugar primordial no fazer poético ovidiano, e o poeta mantém com ela uma relação necessária.

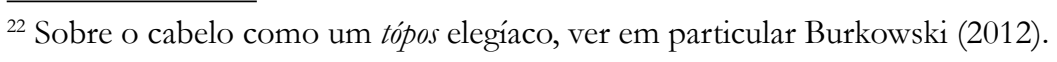


Sendo Roma o espaço em que Ovídio pretende exercer sua autoridade, será sempre Roma o centro cultural capaz de autorizar sua produção poética.

Em Tr. 5.7.55-60, Ovídio uma vez mais se queixa de que sua qualidade poética se vê danificada pelo novo entorno. A diferença com Tr. 3.10 está em que sua desesperança foi consolidada pela passagem do tempo e os traços bárbaros do seu entorno começam a se refletir na sua poesia. Antes desta epístola, em Tr. 3.14.33-50 já se lamenta a incipiente perda do latim:

Dicere saepe aliquid conanti - turpe fateri-

verba mihi desunt dedidicique loqui. ( $\operatorname{Tr}$. 3.14.46)

Amiúde, ao tentar dizer algo - vergonhoso reconhecê-lo! - me faltam as palavras e desaprendi a falar.

Afirmações similares encontram-se também em outras epístolas do exílio, inclusive em $\operatorname{Tr} .5 .7$ :

Sarmatico cogor plurima more loqui et pudet et fateor, iam desuetudine longa

vix subeunt ipsi verba Latina mihi. (Tr. 5.7.56-8)

Sou forçado a falar muitas coisas em língua sarmática e me envergonho e o confesso, já que pela longa falta de uso a mim mesmo mal me brotam palavras em latim.

Ipse mihi videor iam dedidicisse Latine:

nam dedici Getice Sarmaticeque loqui. (Tr. 5.12.57-8)

Parece-me que eu mesmo já desaprendi o latim: pois aprendi a falar gético e sarmático.

Nam dedici Getice Sarmaticeque loqui. (Pont. 3.2.40)

Pois aprendi a falar gético e sarmático.

Sobre a afirmação de Tr. 3.14, Trevizam e Avellar apontam:

Diante de ambiente tão hostil, também Nasão se barbariza. Cercado pelas línguas dos povos da região, o eu-poético parece ter transferidas para si as características deles, a ponto de descrever-se como bárbaro. Nasão afirma ter desaprendido o latim e ter-se tornado falante de gético, ter perdido as habilidades poéticas e não mais escrever versos de qualidade, como se as propriedades do lugar inculto em que vive tivessem determinado seu novo caráter. Deste modo, diante da rude ambiência de exílio, o eu-poético tornase também ele um "outro" (Trevizam; Avellar, 2016, p. 120). 
O relegatus, com efeito, assume que suas habilidades poéticas sofrem pela adversidade enfrentada e, portanto, começa a esquecer o latim. Embora em Tr. 3.14.46 o poeta afirme ter desaprendido o latim, na maioria das vezes ele não admite ter desaprendido completamente sua língua materna, mas não a utilizar com frequência, o que pode se deduzir a partir dos advérbios e verbos que utiliza para manifestar a queixa (Tr. 3.14.45: saepe; Tr. 5.7.58: vix; Tr. 5.12.57: videor). Inclusive, no momento em que afirma estar começando a desaprender o latim, confirma sua habilidade poética ao construir um dístico cuja cacofonia imitaria o som bárbaro que o rodeia: dedidicique loqui (Tr. 3.14.46), Sarmatico cogor (Tr. 5.7.56), dedidicisse Latine: nam dedici Getice Sarmaticeque loqui. (Tr. 5.12.57-8). A sagacidade ovidiana se manifesta nestas linhas, na medida em que, na construção de sua exemplaridade, Ovídio constrói também versos modelos, já que funcionam como exemplum do processo que está a descrever.

O exercício praticado por Ovídio para não perder o uso de sua língua, segundo ele conta em Tr. 5.7.64, é falar consigo mesmo e assim reavivar palavras quase em desuso. Consequentemente, não asseveraríamos a barbarização do poeta. A persona relegata não se tornaria um "outro", como afirmam os autores agora citados, simplesmente porque ela já era um "outro" para os getas. Ele é um romano, e essa diferenciação mantém-se nos poemas, em parte, por meio do distanciamento mencionado supra. A barbarização não é confirmada, mas sim o medo de se barbarizar (Tr. 3.14.49-50: "crede mihi, timeo ne Sintia mixta Latinis / inque meis scriptis Pontica verba legas / "acredita em mim, temo que leias em meus escritos palavras síntias e pônticas misturadas com latinas”), por estar forçado a falar outra língua ("sarmatico cogor plurima more loqui" / "sou forçado a falar muitas coisas em língua sarmática", Tr. 5.7.56). Isso agrega carga patética à caraterização do exilado. Se essa persona cuja autoridade está a se erigir fosse representada como bárbara, o poeta cairia numa contradição. Ovídio quer ser acreditado, quer ser lido e respeitado em Roma, quer ter a autoridade que merece para falar sobre o exílio e suas consequências - inclusive linguísticas. Uma pessoa barbarizada perderia a empatia com o público alvo das epístolas. Prova dessa autoridade ovidiana é a criação a partir de sua poética do tópos da perda da linguagem em situação adversa. Sêneca, por exemplo, em De Consolatione ad Polybium 18.9, "culpa por sua perda da capacidade de falar fluente e aceitavelmente latim ao exílio, da mesma maneira como Ovídio o faz em 3.14" (Natoli, 2017, p. 82). ${ }^{23}$ Natoli, ao analisar o trecho mencionado de Sêneca, cita a acertada observação de Hinds. Este autor nota que Sêneca está na Córsega e não nos confins do Império, como Ovídio. Portanto, sua afirmação seria pelo menos exagerada (Hinds, 2011, p. 62 apud Natoli, 2017, p. 82). A partir disso Natoli conclui, e nos alinhamos a essa posição, que o retrato apresentado por Sêneca sobre o sofrimento linguístico no exílio responde ao tópos criado por Ovídio (Natoli, 2017, p. 82).

23 " [...] blames his loss of ability to speak fluent and acceptable Latin on his exilic location in the same manner in which Ovid had done in Tristia 3. 14". 
A importância como poeta e como autoridade poética para falar sobre o exílio, ademais, é acentuada por Ovídio ao se referir a si mesmo como vates. Sobre o uso de vates em lugar de poeta nos poemas do exílio, Galasso afirma:

Na obra composta durante seu exílio, o termo [vates] é utilizado em certos contextos particulares, amiúde oficiais, em parte também porque Ovídio estava buscando garantir para si mesmo uma função e uma claramente definida posição como poeta. Este é o uso de Virgílio ou também, em certos aspectos, de Horácio, em que vates se torna uma expressão da dignidade e da função civil da poesia. [...] O que é notável para Ovídio é o contraste com suas primeiras produções, que se caracterizavam pelo uso desta palavra em trechos frívolos (Galasso, 2014, p. 194, n. 1). ${ }^{24}$

Em sua interpretação de Tr. 1.3, epístola em que Ovídio descreve a última noite em Roma antes de partir a Tomos, Claassen (2009, p. 174) explica que há um ponto de separação entre duas etapas da vida de Ovídio, seu passado e seu presente. Natoli expande este raciocínio e entende que o livro I dos Tristia descreve, na travessia do exílio, sua metamorfose de loquaz vates a um exulsem poder de fala (Natoli, 2017, p. 84). Essa metamorfose, porém, não se sustenta ao longo da poesia do exílio. Mais ainda, é na qualidade de vates que Ovídio apoia sua autoridade para continuar a escrever poesia. Este lugar de autoridade dado pela condição de vates, dirá mais tarde o próprio Ovídio, é justificado pela matéria da poesia, que trata sobre os gentis Iuleae nomina sancta (Pont. 1.1.46). Depois da declaração do assunto, o poeta continua dizendo:

Vaticinor moneoque: locum date sacra ferenti; non mihi, sed magno poscitur ille deo. (Pont.1.1.47-8)

Vaticino e advirto: dai lugar a quem carrega coisas sagradas; ele o requer não para mim, mas para um grande deus.

Nesta primeira aparição do motivo do vates em Ex Ponto, Ovídio reclama para si a autoridade merecida ao usar o verbo vaticinare, que carrega o sentido religioso de dizer algo inspirado por uma divindade. O lugar de respeito que lhe corresponde, inclusive, é reclamado pelo próprio princeps (ille, v. 48). Nestes versos, a autoridade política de Augusto é utilizada como argumento para defender a autoridade poética de Ovídio.

24 "In the work composed during his exile the term [vates] is utilized in certain particular, often official, context, partly also because Ovid was seeking to secure for himself a function and a clearly defined position as a poet. This is the use of Virgil or also, in certain respects, of Horace, in which vates becomes an expression of the dignity and civil function of poetry. [...] What is noteworthy for Ovid is the contrast with his early production, which was characterized by the use of this word in frivolous passages." Ver também Commager (1962, p. 14-5) sobre a frivolidade do uso de vates nos poemas amatórios de Ovídio. 
Em Tr. 5.7 Ovídio utiliza vates em duas oportunidades. Em primeiro lugar, no verso 22, em posição enfática ao final do primeiro hemistíquio do pentâmetro. Ovídio se refere a si mesmo como um vates em terra hostil. Haveria, no entanto, uma descontinuidade com sua obra anterior, como afirma no verso 21 ("lusorum oblitus amorum" / "esquecido dos amores brincalhões"). Contudo, essa ruptura seria aparente, já que a seguinte aparição de vates alude diretamente a sua obra anterior, mais precisamente aos Amores, como veremos logo a seguir.

A segunda ocorrência do termo é no verso 55: "ille ego Romanus vates - ignoscite, Musae" ("eu aquele vate romano - perdoem, Musas!"). Dado que vates costuma referir-se à sacralidade do poeta e a sua inspiração divina das Musas a quem o poeta rende culto, pode-se ler neste verso uma resposta a Amores 3.8.23: "ille ego Musarum purus Phoebique sacerdos" ("eu aquele puro sacerdote das Musas e de Febo"). A alusão é assinalada pela repetição do começo ille ego e pela referência às Musas. Ovídio recorda seu passado como Musarum sacerdos, ${ }^{25}$ mas afirma uma continuação no labor poético. Mesmo com falhas e menor qualidade, continua se dedicando à poesia (Tr. 5.7.64-8). Continua sendo um vates Romanus (consagrado já desde Met.15.879). Relegado a uma terra onde já não existe a língua grega (Tr. 5.7.51), e sem alguém que saiba falar latim (Tr. 5.7.54), ille Romanus vates é o último vestígio de civilização no meio da barbárie.

\section{REFERÊNCIAS}

ANDRÉ, Jacques. Epistulae ex Ponto (Pontiques). Texte établi et traduit par J. ANDRÉ. Paris: Les Belles Lettres, 1977.

BURKOWSKI, Jane M. C. The symbolism and rhetoric of hair in Latin elegy. Thesis (Doctor of Philosophy in Classical Languages and Literature) - DPhil in Classical Languages and Literature, University of Oxford, Oxford, 2012. Disponível em: https://ora.ox.ac.uk/ objects/uuid:44e36b32-8c44-4dd0-8241-3206e40e67f9. Acesso em: 22 mar. 2020.

CASALI, Sergio. Quaerenti plura legendum: on the necessity of "reading more" in Ovid's exile poetry. Ramus, v. 26, n. 1, p. 80-112, 1997.

CLAASSEN, Jo Marie. Displaced persons: the literature of exile from Cicero to Boethius. London: Duckworth, 1999.

CLAASSEN, Jo Marie. Ovid's poems from exile: the creation of a myth and the triumph of poetry. Antike und Abendland, v. 2, n. 34, p. 158-69, 1988.

${ }^{25} \mathrm{O}$ epíteto de Musarum sacerdos ganha ainda mais relevância pelo fato de que é assim que Horácio refere-se a si mesmo no começo das chamadas Odes romanas (Carm. 3.1.3). Este epíteto teria como propósito isolar as odes romanas do resto do corpus (Commager, 1962, p. 16), além de conferir grande peso e autoridade a seu pronunciamento como vate (Syndikus, 2010, p. 194). 
CLAASSEN, Jo Marie. Ovid's poetic Pontus. Papers of the Leeds International Latin Seminar, v. 6, p. 29-45, 1990.

CLAASSEN, Jo Marie. Tristia. In: KNOX, P. (ed.). A companion to Ovid. London: Blackwell, 2009.

COMMAGER, Steele. The odes of Horace. A critical study. Norman: The University of Oklahoma Press, 1962.

EVANS, Harry B. Winter and warfare in Ovid's Tomis: (Tristia 3.10). The Classical Journal, v. 70, n. 3, p. 1-9, 1975.

GALASSO, Luigi. The Ars poetica of Horace in Ovid's exile poetry. Materiali e discussioni per l'analisi dei testi classici, n. 72, p. 193-205, 2014.

HELZLE, Martin. Bryn Mawr Classical Review to Gareth Williams, The curse of exile: a study of Ovid's Ibis. BMCR, 1997. Disponível em: https://bmcr.brynmawr.edu/1997/1997.07.05/. Acesso em: 22 mar. 2020.

HELZLE, Martin. Publii Ovidii Nasonis Epistularum ex Ponto liber IV. Hildescheim: Olms, 1989.

HINDS, Stephen. Seneca's Ovidian Loci. Studi Italiani di Filologia Classica, quarta serie, v. 9, p. 5-63, 2011.

HOLZBERG, Niklas. Ovid: the poet and his work. Ithaca: Cornell University Press, 2006.

INGLEHEART, Jennifer. Ovid, the error and the theme of sight in Tristia 2. Materiali e discussioni per l'analisi dei testi classici, n. 56, p. 63-86, 2006.

LATEINER, Donald. Mimetic syntax: metaphor from word order, especially in Ovid. The American Journal of Philology, v. 111, n. 2, p. 204-37, 1990.

LUCK, G. P. (ed.). Ovidius Naso, Tristia. Heidelberg: Carl Winter, 1967. v. 1.

MARTIN, Anna Julia. Was ist exil? Ovids Tristia und Epistulae ex Ponto. Hildescheim: Olms, 2001. (Spudasmata, 99.).

MICHALOPOULOS, Andreas. Famaque cum domino fugit ab urbe suo: aspectos da fama na poesia de exílio de Ovídio. Codex, v. 4, n. 1, p. 79-95, 2016.

DOI: https://doi.org/10.25187/codex.v4i1.3336

NAGLE, Betty Rose. Ovid's Fasti: Roman holidays. Bloomington: Indiana University Press, 1995.

NAGLE, Betty Rose. The poetics of exile: program andpolemic in the Tristia and Epistulae ex Ponto of Ovid. Bruxelas: Latomus, 1980. (Latomus, 170).

NATOLI, Bartolo. Silenced voices. The poetics of speech in Ovid. Madison: The Wisconsin University Press, 2017.

ROSATI, Gianpiero. P. Ovidii Nasonis Heroidum Epistulae XVIII-XIX Leander Heroni - Hero Leandro. Firenze: Le Monnier, 1996. 
SINDIKUS, Hans Peter. The Roman Odes. In: DAVIS, G. (ed.). A companion to Horace. Oxford: Wiley-Blackwell, 2010.

STANFORD, William Bedell. The sound of Greek. Cambridge: Cambridge University Press, 1967.

THIBAULT, John C. The mystery of Ovid's exile. Berkeley: University of California Press, 1964. THOMAS, Richard. Lands and people in Roman poetry: the ethnographical tradition. Cambridge: Cambridge Philological Society, 1982.

TREVIZAM, Matheus; AVELLAR, Julia. B. C. Os citas e a Cítia em Geórgicas 3.349-383 e em Tristia 3.10: permanência de parâmetros e intertextualidade. PhaoS, v. 16, p. 105-23, 2016. https://econtents.bc.unicamp.br/inpec/index.php/phaos/article/view/9437

WILLIAMS, Garreth. Banished voices: readings in Ovid's exile poetry. Cambridge: Cambridge University Press, 1994.

WILLIAMS, Garreth. The curse of exile: a study of Ovid's Ibis. Cambridge: Cambridge Philological Society, 1996. 